\title{
Immunogenicity of chloroplast-derived HIV-1 p24 and a p24-Nef fusion protein following subcutaneous and oral administration in mice
}

\author{
Nuria Gonzalez-Rabade ${ }^{1}$,Edward G. McGowan ${ }^{2, \dagger}$, Fei Zhou ${ }^{3, \S}$, Matthew S. McCabe ${ }^{4, \ddagger}$, Ralph Bock ${ }^{3}$, \\ Philip J. Dix ${ }^{4}$, John C. Gray ${ }^{1, *}$ and Julian K-C. Ma ${ }^{2}$ \\ ${ }^{1}$ Department of Plant Sciences, University of Cambridge, Cambridge, UK \\ ${ }^{2}$ Division of Cellular and Molecular Medicine, St George's, University of London, London, UK \\ ${ }^{3}$ Max-Planck-Institut für Molekulare Pflanzenphysiologie, Am Mühlenberg, Potsdam-Golm, Germany \\ ${ }^{4}$ Department of Biology, National University of Ireland, Maynooth, Co. Kildare, Ireland
}

Received 14 September 2010;

revised 27 January 2011;

accepted 28 January 2011.

*Correspondence (fax +44 1223 333953; email jcg2@cam.ac.uk)

†Present address: Biochemical Screening, Ablynx S.A., Rua do Campo Alegre 1021 4150-180 Porto, Portugal.

¥Present address: Animal and Bioscience

Research Department, Animal and Grassland Research and Innovation Centre Teagasc, Grange, Dunsany, Co. Meath, Ireland.

§Present address: National Key Laboratory of Crop Genetic improvement, College of Life Science and Technology, Huazhong Agricultural University, China.

Keywords: chloroplast, HIV, oral vaccine, p24, Nef, tobacco.

\begin{abstract}
Summary
High-level expression of foreign proteins in chloroplasts of transplastomic plants provides excellent opportunities for the development of oral vaccines against a range of debilitating or fatal diseases. The HIV-1 capsid protein p24 and a fusion of p24 with the negative regulatory protein Nef (p24-Nef) accumulate to $\sim 4 \%$ and $\sim 40 \%$ of the total soluble protein of leaves of transplastomic tobacco (Nicotiana tabacum L.) plants. This study has investigated the immunogenicity in mice of these two HIV-1 proteins, using cholera toxin B subunit as an adjuvant. Subcutaneous immunization with purified chloroplast-derived p24 elicited a strong antigen-specific serum IgG response, comparable to that produced by Escherichia coli-derived p24. Oral administration of a partially purified preparation of chloroplast-derived p24-Nef fusion protein, used as a booster after subcutaneous injection with either p24 or Nef, also elicited strong antigen-specific serum IgG responses. Both $\lg G 1$ and $\lg G 2$ a subtypes, associated with cell-mediated Th1 and humoral Th2 responses, respectively, were found in sera after subcutaneous and oral administration. These results indicate that chloroplast-derived HIV-1 p24-Nef is a promising candidate as a component of a subunit vaccine delivered by oral boosting, after subcutaneous priming by injection of p24 and/or Nef.
\end{abstract}

\section{Introduction}

Acquired immunodeficiency syndrome (AIDS) is caused by infection with the human immunodeficiency virus, HIV, which apparently spread to the human population from non-human African primates during the 20th century (Gallo, 2006). Around 33 million HIV infections were estimated worldwide in 2007, and a large number of these infections are located in developing countries (WHO, 2009). A safe and effective vaccine to reduce the transmission of HIV-1 infection or to prevent disease progression is desperately needed, particularly in developing countries (Essex, 1999). However, the development of a vaccine for HIV has proved to be very difficult, partly because of the complex nature of the virus (Crandall, 2001). HIV is highly adaptable because of its high mutation rate and there are multiple strains belonging to a number of different clades (Spira et al., 2003), so it is likely that a multi-component vaccine comprising several proteins or peptides will be necessary to invoke broad and potent immunity. Subunit vaccines offer the advantage of targeting specific epitopes that lie within conserved areas of the virus. Two potential antigens, the 24-kDa capsid protein p24 and the $31-\mathrm{kDa}$ regulatory protein Nef, are the focus of this study. The core protein p24 has $80 \%$ conservation of identical amino acids across HIV-1 clades because of structure/function constraints (Hanke and McMichael, 2000), whereas Nef has a sequence identity of $84 \%$ and an average similarity of $89 \%$ between five different subtypes (Geyer and Peterlin, 2001).

Structural proteins, such as p24, are good candidates for vaccine components because of their high conservation (Novitsky et al., 2001). In other virus infections, like hepatitis B and influenza, immune responses directed at the viral core protein have been shown to be protective (Russell and Liew, 1980; Iwarson et al., 1985; Murray et al., 1987). Nef, on the other hand, is an indispensable early post-infection regulatory protein ( $\mathrm{Hel}$ et al., 2002a). Studies in non-human primates have shown that vaccineinduced cytotoxic T-lymphocyte responses against early proteins, such as Nef, provide a degree of protection against pathogenic virus challenges (Hel et al., 2002a). Both HIV p24 and Nef have been part of several immunological trials and have shown the capacity to induce strong, multi-epitopic CD4+ and CD8+ T-cell responses (McMichael and Hanke, 2003; Girard et al., 2006). Also, an immunogenicity study with a plant-derived p24-lg antigen-antibody fusion showed T-cell responses in mice (Obregon et al., 2006). Cell-mediated immune responses against regulatory proteins such as Nef may eliminate virus-infected cells at an early 
stage of viral replication, whereas cell-mediated immune responses against the core protein p24 may eliminate infected cells by specific cytolysis (Asakura et al., 1997). Both of these HIV proteins are thus clear targets for a multi-component vaccine. A vaccine containing both proteins may increase the probability of achieving a long-lasting, efficient immune response.

HIV-1 p24 has previously been prepared in Escherichia coli (Marczinovits et al., 1993; Hausdorf et al., 1994), yeast (Weber et al., 1995), baculovirus (Mills and Jones, 1990) and in tobacco, using transient expression (Zhang et al., 2000; Meyers et al., 2008), stable nuclear transformation (Zhang et al., 2002; Meyers et al., 2008) or chloroplast transformation (McCabe et al., 2008; Zhou et al., 2008). HIV-1 Nef has been produced in E. coli (Kohleisen et al., 1996), transgenic tobacco (Marusic et al., 2007) and transplastomic tobacco (Zhou et al., 2008). The p24 accumulation levels obtained in these systems vary from $12 \mathrm{mg} / \mathrm{L}$ of rich medium in the E. coli system (Hausdorf et al., 1994), $50 \mathrm{mg} / \mathrm{L}$ of culture in the baculovirus system (Mills and Jones, 1990), $\sim 1 \mathrm{mg} / \mathrm{kg}$ fresh weight of leaves for the transient protein expression system (Meyers et al., 2008), $\sim 35 \mathrm{mg} / \mathrm{kg}$ leaf soluble protein in transgenic tobacco (Zhang et al., 2002) and $\sim 450 \mathrm{mg} / \mathrm{kg}$ fresh weight in transplastomic plants (McCabe et al., 2008). The accumulation levels obtained through chloroplast transformation are much higher than those achieved in other systems (Oey et al., 2009; Bock and Warzecha, 2010; Ruhlman et al., 2010), and the antigens used in this study, p24 and p24-Nef, accumulate to $\sim 4 \%$ and $\sim 40 \%$ of total soluble leaf protein (Zhou et al., 2008). These levels are likely to satisfy the demand for p24 and Nef as part of an HIV vaccination programme, especially if large quantities are required, as would probably be the case for an oral vaccine targeted to developing countries.

Oral vaccines are likely to be in greater demand in developing countries, because of ease of administration and no requirement for specialized personnel or an uninterrupted cool chain. Also, they are better suited to produce mucosal responses, essential for pathogens, such as HIV, that invade via these sites. Antigens produced in plants may be enriched or partially purified prior to oral administration, or may simply be delivered as a tissue homogenate without any purification, because oral vaccines do not require a high amount of purity (Walmsley and Arntzen, 2003; Daniell et al., 2009). Vaccination with tissue homogenates may provide some protection, by bioencapsulation of the antigen, against degradation or dilution in the digestive system. Oral administration of chloroplast-derived antigens has resulted in successful vaccination of mice against several proteins, including tetanus toxin (Tregoning et al., 2005), a plague fusion protein (Arlen et al., 2008), an E. coli enterotoxin fusion protein (Rosales-Mendoza et al., 2009) and cholera toxinmalaria antigen fusion proteins (Davoodi-Semiromi et al., 2010). Here, the immunogenicity of tobacco chloroplast-derived p24 and a p24-Nef fusion protein was examined in mice following subcutaneous injection of purified p24 and oral gavage of enriched p24-Nef, partially purified to deplete potentially toxic polyphenols and alkaloids, such as nicotine.

\section{Results}

\section{Systemic immunogenicity of chloroplast-derived p24}

Initially, the immunogenicity in mice of tobacco chloroplastderived p24 was compared to E. coli-derived p24, which is known to be antigenic (Iroegbu et al., 2000). p24 was purified
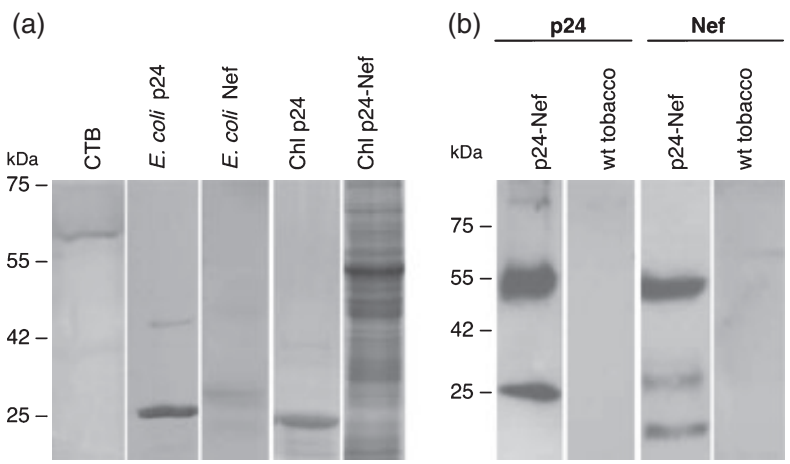

Figure 1 Antigens and adjuvant used for immunizations. Samples were separated by electrophoresis in SDS $12 \%$ polyacrylamide gels. (a) Coo-

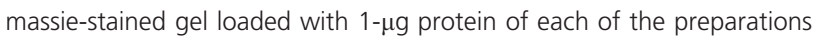
used for injection. From left to right, Vibrio cholerae cholera toxin B subunit ( $\sim 60 \mathrm{kDa})$, Escherichia coli-derived HIV-1 p24 ( 25 kDa), E. coliderived HIV-1 Nef ( 27 kDa), tobacco chloroplast (Chl)-derived HIV-1 p24 ( $24 \mathrm{kDa})$ and $20 \mu \mathrm{L}$ of a suspension ( $0.1 \mathrm{~g}$ freeze-dried powder in $5 \mathrm{~mL}$ water) of partially purified tobacco Chl-derived HIV-1 p24-Nef. (b) Western blots of a gel loaded with $20 \mu \mathrm{L}$ of a suspension of the partially purified chloroplast-derived p24-Nef preparation and of a sample prepared in the same way from wild-type (wt) tobacco leaves. The antibodies used are indicated at the top (anti-p24 or anti-Nef). The position of the marker proteins (low range; Bio-Rad) is shown on the left-hand side of each part of the figure.

to $>95 \%$ homogeneity from transplastomic tobacco plants (cultivar Maryland Mammoth) by a simple procedure involving ammonium sulphate precipitation and cation-exchange chromatography on Mono S-Sepharose (McCabe et al., 2008). The material was assessed by SDS-PAGE and Coomassie-staining and showed a single polypeptide of $\sim 24 \mathrm{kDa}$ (Figure 1a). p24 was produced in E. coli as a His ${ }_{10}$-tagged protein and was purified from inclusion bodies on Ni-NTA agarose in the presence of $8 \mathrm{~m}$ urea (Zhou et al., 2008). Following lipopolysaccharide removal, the endotoxin-free preparation resolved as a predominantly $25-\mathrm{kDa}$ band (because of the presence of the His $10^{-t a g}$ ), with a small amount of higher molecular weight material (Figure 1a). This figure also shows the Vibrio cholerae cholera toxin B subunit (CTB) preparation which was used as an adjuvant in all immunizations; the predominant band at $\sim 60 \mathrm{kDa}$ is the tightly linked pentameric form of $12 \mathrm{kDa}$ B subunits. CTB has been shown to enhance antigen presentation, promote isotype differentiation in B cells and stimulate T-cell proliferation and lymphokine production, without generating unexpected adverse responses (Holmgren et al., 1992).

Four groups of mice were used to compare the immunogenicity of chloroplast-derived p24 and E. coli-derived p24. Two groups were injected subcutaneously with 10 or $1 \mu \mathrm{g}$ of chloroplast-derived p24, and the other two groups received either 10- $\mu$ g E. coli-derived p24 or phosphate/citrate buffer pH 7.0, as a negative control. Antibodies to p24 appeared after the first immunization with the high dose of chloroplast-derived p24 and with E. coli-derived p24, and the antibody responses increased after each subsequent injection (Figure 2a). Serial dilutions of the sera gave similar end-point titres $(\sim 1: 6400)$ for both chloroplast- and E. coli-derived p24 (Table 1). Antigenspecific $\lg G$ was not detected in the preimmune sera (day -1 ), nor in the sera from the buffer control group. The group that received the low dose $(1 \mu \mathrm{g})$ of chloroplast-p24 showed a very 

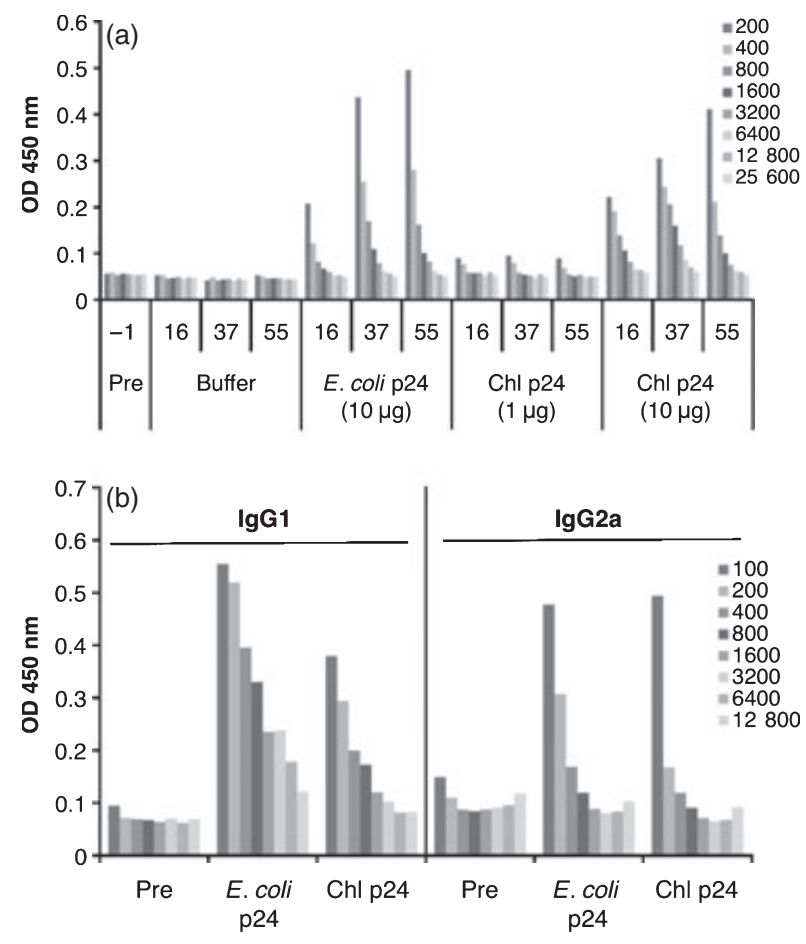

Figure 2 Analysis of antibody (lgG) response following subcutaneous administration of chloroplast-derived (Chl) and Escherichia coli-derived HIV-1 p24. Four groups of six female 5-week-old C57BL/6J mice were injected subcutaneously with 10 or $1 \mu \mathrm{g}$ of chloroplast-derived p24, $10-\mu \mathrm{g}$ E. coli-derived p24 or phosphate/citrate buffer pH 7.0, as a negative control. All injections included $10-\mu \mathrm{g}$ cholera toxin B subunit as an adjuvant. Mice were immunized on days 1, 17 and 38, before culling on day 55. Blood samples were taken 1 day before each immunization, and on day 55. Serum samples from each group of mice were pooled at each time point, and serial twofold dilutions (shown on the right) were analysed by p24-specific ELISA using wells coated with chloroplastderived p24 and horseradish peroxidase-linked sheep anti-mouse IgG to detect the bound p24-specific antibodies. (a) p24-specific IgG antibody titres of serum samples after the different immunization time points (days are indicated on the $x$ axis). (b) IgG subtype analysis showing p24-specific IgG1 and IgG2a antibody titres of pre-immunization and cull (day 55) serum samples of high-dose (10- $\mu \mathrm{g}$ p24) groups.

low antibody response (titre of $\sim 1: 800$ ). This analysis clearly demonstrated that chloroplast-derived p24 was immunogenic when injected subcutaneously and did not differ substantially from E. coli-derived p24.

The profile of antibody isotype responses, assessing the presence of p24-specific $\lg \mathrm{g} 1$ and $\lg$ 22a subtypes in sera, was determined by ELISA on pooled cull serum samples (Figure $2 b$ ). The group that received the high dose $(10 \mu \mathrm{g})$ of chloroplastderived p24 showed p24-specific $\operatorname{lgG} 1$ and $\lg G 2 a$ responses, with titres of up to $1: 6400$ for $\operatorname{lgG} 1$ and $1: 3200$ for $\lg 22 a$ (Table 1). The group that received E. coli-derived p24 also presented both subtypes of $\mathrm{IgG}$, with a slightly higher titre (>1: 12800) of $\lg 1$ than achieved with chloroplast-derived p24 and similar titres ( 1: 3200) for IgG2a (Figure 2b). This systemic IgG subtype analysis indicates the involvement of both cell-mediated immune responses, via Th1 helper cells and $\operatorname{lgG} 2 \mathrm{a}$, and humoral immune responses, via Th2 helper cells and $\lg \mathrm{G} 1$.

\section{Oral immunogenicity of chloroplast-derived p24-Nef}

The accumulation of the p24-Nef fusion protein in chloroplasts of transplastomic tobacco was much higher ( 40\% TSP) than the accumulation of either p24 ( 4\% TSP) or Nef individually (Zhou et al., 2008), making it a favoured candidate for oral administration. However, tobacco leaves contain large amounts of phenolics and toxic alkaloids, such as nicotine, which might compromise oral delivery. A partial purification protocol resulting in the removal of most of the polyphenolic compounds and alkaloids was developed. Transplastomic tobacco leaves (cultivar Petite Havana) were homogenized in four volumes of extraction buffer containing 20\% (w/v) Dowex-1 resin, which has been shown to remove $>95 \%$ of leaf polyphenols (Gray, 1978). Some contaminating protein was removed from the leaf extract by precipitation at $\mathrm{pH} 5.0$ and by passage through an anionexchange Vivapure Q spin column, recovering the flow-through. The protein content of the extract was decreased by $\sim 40 \%$, whereas the p24-Nef content, as assessed by p24-specific ELISA, remained the same. Following dialysis against $10 \mathrm{~mm}$ $\left(\mathrm{NH}_{4}\right)_{2} \mathrm{CO}_{3}$, the extract was lyophilized, yielding $\sim 2.5 \mathrm{~g}$ of powder from $100 \mathrm{~g}$ of leaves. SDS-PAGE of the lyophilized material showed a prominent Coomassie-stained band at $55 \mathrm{kDa}$ against a background of a range of other polypeptides (Figure 1a). Antibodies to p24 and to Nef both detected a predominant $55 \mathrm{kDa}$ polypeptide, of the expected size for a p24-Nef fusion protein, on Western blots (Figure 1b). Additional immunoreactive bands of $\sim 20-25 \mathrm{kDa}$ may represent cleaved monomeric p24 or Nef polypeptides or degradation products.

The nicotine contents of the leaves and the lyophilized leaf extract were assessed by HPLC following extraction with acidified methanol. Leaves contained $12.2 \pm 2.3 \mathrm{nmol}$ nicotine per mg fresh weight ( $\sim 2 \mathrm{mg}$ nicotine per $\mathrm{g}$ fresh weight), which is comparable to published amounts for other cultivars (Djordjevic and Doran, 2009). The partially purified leaf extract contained the equivalent of $0.25 \mathrm{nmol}$ nicotine per $\mathrm{mg}$ fresh leaf, representing a $>95 \%$ reduction in nicotine content, and providing material for oral administration by gavage that contained $168 \mu \mathrm{g}$ nicotine per dose.

Five groups of mice were used to assess the oral immunogenicity of chloroplast-derived p24-Nef, and to compare the response to that obtained by oral administration of p24 or Nef, expressed in E. coli. Each of these groups received doses of $50 \mu \mathrm{g}$ of antigen (p24-Nef, p24 or Nef), administered by oral gavage. A negative control group received the equivalent amount of wild-type tobacco leaf extract, processed in exactly the same way as tobacco expressing the p24-Nef fusion protein, but not containing any immunoreactive p24 or Nef proteins (Figure $1 \mathrm{~b}$ ). In addition, one further group of mice was primed subcutaneously with both $10-\mu \mathrm{g}$ E. coli-derived p24 and

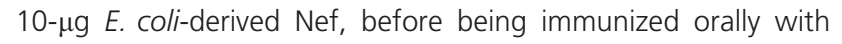
$50-\mu \mathrm{g}$ chloroplast-derived p24-Nef. CTB $(10 \mu \mathrm{g})$ was included as an adjuvant in all immunizations. Serum samples were analysed for the presence of p24- and Nef-specific IgG antibodies by ELISA. The titres reached by each group at the different time points are shown in Figure $3 a$ (p24-specific responses) and in Figure 3b (Nef-specific responses).

Only E. coli-derived p24 elicited a good p24-specific IgG response among the groups receiving only orally administered antigens, although three immunizations were required to reach the maximum response. Administering three doses of $50 \mu \mathrm{g}$ of tobacco-derived p24-Nef, by gavage, did not prompt a serum 
Table 1 Endpoint titres of ELISA assays for antigen-specific IgGs in cull serum samples. The endpoint titre is defined as the reciprocal of the highest serum dilution that gave a reading above that of the pre-immunization serum or of the negative control group. Only dilutions up to $1: 800$ were assayed for $\lg G 1$ and $\lg G 2 a$ subtypes in the serum samples from the prime-boost experiment in Figure 4

\begin{tabular}{|c|c|c|c|c|}
\hline Immunization & $\lg G$ titre & $\operatorname{lgG} 1$ titre & IgG2a titre & $\lg G 1: \lg G 2 a$ ratio \\
\hline Escherichia coli p24 (10 $\mu \mathrm{g}) \mathrm{SC}$ & 6400 & 12800 & 3200 & 4.0 \\
\hline Chl p24 (1 $\mu \mathrm{g}) \mathrm{SC}$ & 800 & 800 & 400 & 2.0 \\
\hline Chl p24 $(10 \mu \mathrm{g}) \mathrm{SC}$ & 6400 & 6400 & 3200 & 2.0 \\
\hline Chl p24-Nef $(50 \mu g)$ Oral & - & - & - & - \\
\hline E. coli p24 $(50 \mu \mathrm{g})$ Oral & 12800 & $>800$ & 200 & $>4$ \\
\hline E. coli Nef $(50 \mu \mathrm{g})$ Oral & - & - & - & - \\
\hline \multirow[t]{2}{*}{ E. coli p24 \& Nef $(10 \mu \mathrm{g}) \mathrm{SC}+\mathrm{Chl}$ p24-Nef $(50 \mu \mathrm{g})$ Oral } & 12800 (p24) & $>800$ & $>800$ & $\sim 1(\mathrm{p} 24)$ \\
\hline & 6400 (Nef) & $>800$ & 400 & $>2$ (Nef) \\
\hline E. coli p24 $(10 \mu \mathrm{g}) \mathrm{SC}+\mathrm{Chl}$ p24-Nef $(50 \mu \mathrm{g})$ Oral & $>12800$ & $>800$ & $>800$ & $\sim 2$ \\
\hline E. coli p24 $(10 \mu \mathrm{g}) \mathrm{SC}$ & 3200 & $>800$ & $>800$ & $\sim 2$ \\
\hline E. coli p24 $(10 \mu \mathrm{g}) \mathrm{SC}+$ E. coli p24 $(50 \mu \mathrm{g})$ Oral & 6400 & $>800$ & $>800$ & $\sim 1$ \\
\hline E. coli Nef $(10 \mu \mathrm{g}) \mathrm{SC}+\mathrm{Chl}$ p24-Nef $(50 \mu \mathrm{g})$ Oral & 3200 & $>800$ & 800 & $\sim 2$ \\
\hline E. coli Nef $(10 \mu \mathrm{g}) \mathrm{SC}$ & 400 & 200 & 100 & 2.0 \\
\hline E. coli Nef $(10 \mu \mathrm{g}) \mathrm{SC}+$ E. coli Nef $(50 \mu \mathrm{g})$ Oral & 800 & 400 & 100 & 4.0 \\
\hline
\end{tabular}

SC, subcutaneous.

response to either p24 or Nef. The reason for the lack of response to p24-Nef is unknown. Neither E. coli-derived Nef nor wild-type tobacco extract generated any antigen-specific IgG response when administered orally. However, in the group primed with E. coli p24 and E. coli Nef and boosted with tobacco p24-Nef, specific anti-p24 and anti-Nef antibodies were detected 13 days after priming and greatly increased after boosting with the plant-derived material. The p24-specific response increased approximately threefold after the first oral boost and appeared to be maximal, as there was little further change after the second and third gavages (Figure 3a). The Nef-specific response was somewhat slower, requiring two boosts of p24-Nef before reaching the maximum response (Figure 3b). E. coli-derived Nef was a poor mucosal antigen when delivered orally on its own, failing to generate any appreciable IgG response. However, an anti-Nef IgG response was elicited by priming with $E$. coli-derived Nef and boosting with plant-derived p24-Nef, confirming the mucosal antigenicity of the HIV chloroplast-derived fusion protein.

Analysis of the $\lg G$ subtype on the pooled cull serum samples, by ELISA, showed p24-specific $\lg G 1$ and $\lg G 2 a$ responses in the mice that received E. coli-derived p24 orally (Figure 3c). However, much higher p24-specific $\operatorname{lgG} 1$ and $\lg \mathrm{G} 2 \mathrm{a}$ responses were obtained in the group primed subcutaneously with $E$. coliderived p24 and Nef and boosted orally with plant-derived p24Nef (Figure 3c). These mice also showed a strong Nef-specific IgG1 response, but a weaker Nef-specific lgG2a response, indicating a lower Th1-mediated cellular response to Nef. No antigen-specific IgG subclasses could be detected in sera of mice receiving oral doses of $E$. coli-derived Nef or the leaf extract from wild-type tobacco. This IgG subtype analysis indicated that oral boosting with partially purified p24-Nef fusion protein is able to elicit strong cell-mediated and humoral immune responses against p24, with weaker responses against Nef.

\section{Prime-boost strategy with p24, Nef and p24-Nef}

In view of the strong immune responses obtained in mice primed subcutaneously with E. coli-derived p24 and Nef and boosted orally with chloroplast-derived p24-Nef, a follow-up study was designed to examine further the potential of the prime-boost strategy, comparing priming with either p24 or Nef, and boosting with p24-Nef, p24 or Nef. Purified E. coliderived p24 and Nef and partially purified tobacco p24-Nef were used as in the previous experiment. Six groups of mice were used: three groups were primed subcutaneously with $10-\mu \mathrm{g}$ E. coli-derived p24 and three groups were primed subcutaneously with $10-\mu \mathrm{g} E$. coli-derived Nef. The three p24primed groups were subsequently boosted, by gavage, with either $50-\mu \mathrm{g}$ partially purified tobacco-derived p24-Nef, 50- $\mu \mathrm{g}$ E. coli-derived p24 or phosphate-buffered saline (PBS) (used as a control), whereas the three Nef-primed groups received either $50-\mu \mathrm{g}$ partially purified tobacco-derived p24-Nef, 50- $\mu \mathrm{g}$ E. coliderived Nef or PBS, by gavage. CTB $(10 \mu \mathrm{g})$ was included as an adjuvant in all immunizations.

Analysis of the serum samples by ELISA for p24- and Nefspecific IgG antibodies clearly showed that boosting with tobacco-derived p24-Nef elicited the greatest immune responses (Figure 4). The plant-derived p24-Nef fusion protein was a more potent booster than $E$. coli-derived p24 in eliciting p24-specific antibodies (Figure $4 a$ ) and a more potent booster than E. coliderived Nef in eliciting Nef-specific antibodies (Figure 4b). Only one boost with p24-Nef was necessary to maximize the antip24 IgG response, with subsequent boosts maintaining the response, whereas with p24 as a booster, the response increased with each boost, without ever reaching the anti-p24 IgG titres ( 1: 12800) obtained with tobacco-derived p24-Nef (Figure 4a). In fact, the responses obtained by oral boosting with p24 were not much higher than those obtained by solely priming with $\mathrm{p} 24$. Oral boosting with E. coli-derived Nef was even less effective, with no increased response over that obtained solely by subcutaneous priming with Nef (Figure 4b). Boosting with tobacco-derived p24-Nef, after priming with Nef, elicited a strong Nef-specific response that stabilized after the second oral boost (Figure 4b).

Attempts to detect a mucosal immune response by measurement of p24- and Nef-specific IgA in faecal samples and vaginal 

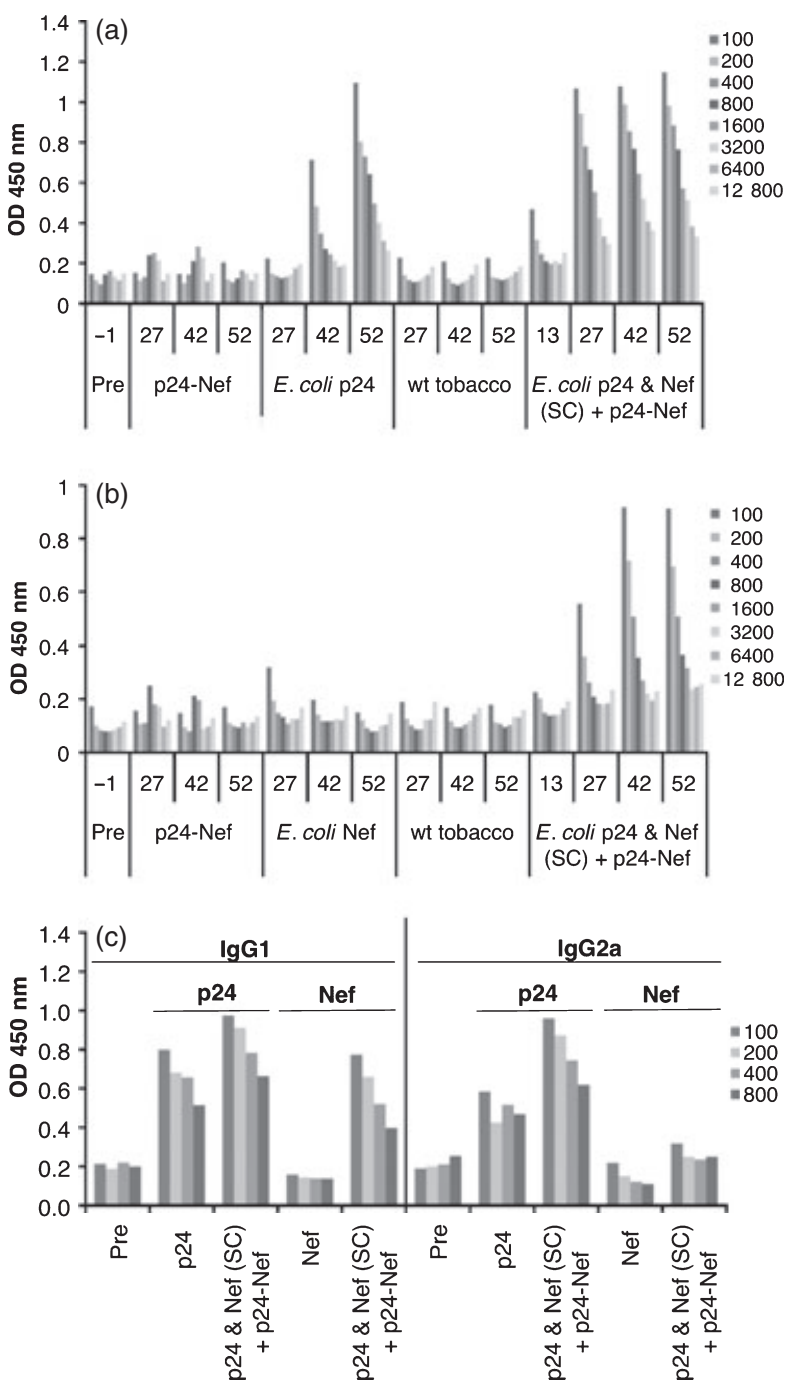

Figure 3 Analysis of antibody (lgG) response following oral administration of tobacco chloroplast-derived p24-Nef. Three groups of six female BALB/C mice received $50 \mu \mathrm{g}$ of antigen (p24-Nef, p24 or Nef) administered by oral gavage, one group was primed subcutaneously with $10-\mu \mathrm{g}$ Escherichia coli-derived p24 and 10- $\mu$ g E. coli-derived Nef, before oral gavage with $50-\mu \mathrm{g}$ chloroplast-derived p24-Nef, and a negative control group received wild-type tobacco leaf extract. All antigens were administered with 10- $\mu \mathrm{g}$ cholera toxin B subunit, as an adjuvant. E. coliderived p24 and Nef were injected subcutaneously on day 1, followed by oral administration of antigens to all groups by gavage on days 14 , 28 and 43. Blood samples were collected 1 day prior to each immunization and on day 52, when the mice were culled. Serum samples from each group of mice were pooled at each time point, and serial twofold dilutions (shown on the right) were analysed for the presence of p24and Nef-specific IgG antibodies by ELISA. (a) p24-specific IgG antibody titres of serum samples, using wells coated with E. coli-derived p24. (b) Nef-specific IgG antibody titres of serum samples, using wells coated with E. coli-derived Nef. (c) IgG subtype analysis showing p24-specific and Nef-specific $\operatorname{lgG} 1$ and $\lg G 2 a$ antibody titres of pre-immunization and cull (day 52) serum samples.

washes by ELISA were unsuccessful. Faecal samples produced a very high background in the ELISAs and vaginal washes gave very low readings, possibly because of excessive dilution of the samples.
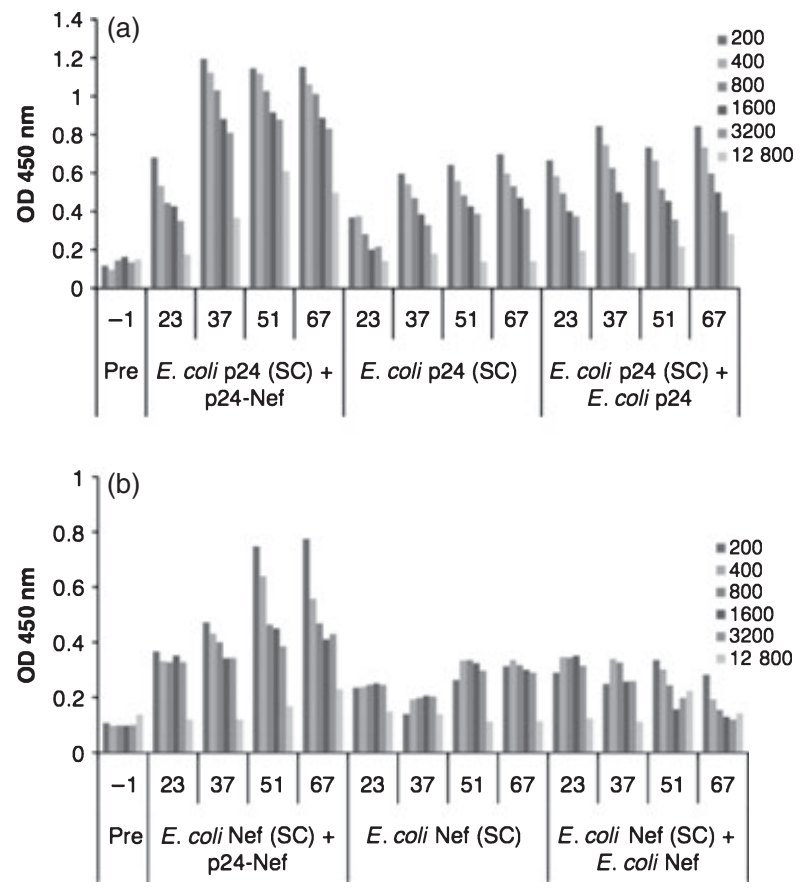

Figure 4 Analysis of antibody (lgG) response following oral administration of tobacco chloroplast-derived p24-Nef, as a booster after subcutaneous administration of Escherichia coli-derived p24 and Nef. Three groups of five BALB/C female mice were primed subcutaneously with $10-\mu \mathrm{g} E$. coli-derived p24 and three groups were primed subcutaneously with $10-\mu \mathrm{g}$ E. coli-derived Nef. The three p24-primed groups were subsequently boosted, by gavage, with either 50- $\mathrm{gg}$ partially purified tobacco-derived p24-Nef, 50- $\mu \mathrm{g}$ E. coli-derived p24 or phosphatebuffered saline (PBS) (as a control), whereas the three Nef-primed groups received either 50- $\mu$ g partially purified tobacco-derived p24-Nef, $50-\mu \mathrm{g}$ E. coli-derived Nef or PBS, by gavage. All preparations were given with 10- $\mu \mathrm{g}$ cholera toxin B subunit as an adjuvant. Antigens were administered on day 1 (priming), 24, 38 and 52 (boosting), before culling on day 67 , and blood samples were collected 1 day before each of the boosts. Serum samples from each group of mice were pooled at each time point, and serial twofold dilutions (shown on the right) were analysed by ELISA for p24- and Nef-specific IgG antibodies. (a) p24-specific IgG antibody titres of serum samples, using wells coated with $E$. coli-derived p24. (b) Nef-specific IgG antibody titres of serum samples, using wells coated with E. coli-derived Nef.

\section{Discussion}

The oral administration of chloroplast-derived HIV-1 p24-Nef has been shown to be an effective means of generating a immune response, targeting both p24 and Nef proteins, following subcutaneous priming with the individual p24 and Nef antigens. The immune response generated was associated with both Th1 and Th2 helper cells, as indicated by the presence of antigen-specific $\lg G 1$ and IgG2a subtypes, suggesting the stimulation of a mixed cell-mediated and humoral response. Such a response has been correlated with a higher degree of protection against intracellular pathogens such as HIV (Johnston and Fauci, 2007). Prime-boost strategies have been widely used against HIV in mice and macaques trials (Haglund et al., 2002; Takeda et al., 2003) and generate strong, broad immune responses that are greater than can be attained by single vaccine strategies. Prime-boost vaccination strategies in other 
studies have shown great potential for stimulation of long-term immune responses (Haglund et al., 2002; Hel et al., 2002b; Takeda et al., 2003; Pal et al., 2005). A subcutaneous primeoral boost strategy has also been successful with other chloroplast-derived antigens, including a plague F1-V fusion protein and CTB-malaria antigen fusions (Arlen et al., 2008; DavoodiSemiromi et al., 2010). Although E. coli-derived p24 was used for subcutaneous priming in the experiments shown in Figures 3 and 4, tobacco chloroplast-derived p24 should be just as effective. The immunogenicity of purified chloroplast-derived p24 was comparable with purified $E$. coli-derived p24 when administered subcutaneously (Figure 2).

In our study, a greater immune response was obtained by oral delivery of p24-Nef as a booster than by boosting with E. coli-derived p24 or Nef antigens. There are several possible explanations for this observation. Firstly, the conformation of p24 and Nef in the p24-Nef fusion protein may be different to the individual proteins and this may enhance their antigenicity in mice through increased exposure or presentation of specific epitopes. Secondly, there may be additional adjuvants in the plant material, which may enhance the immune response in mice. Although CTB was included as an adjuvant in all immunizations, leaves contain relatively large amounts of various members of the Hsp70 and Hsp60 heat-shock protein families (Ellis, 1990; Marshall et al., 1990), which are known to act as adjuvants in other systems (Suzue and Young, 1996; Wang et al., 2002). The Hsp60 chaperonin Cpn60 is the second most abundant protein in chloroplasts (Ellis, 1990) and is homologous to bacterial GroEL/Cpn60 proteins (Hemmingsen et al., 1988) that stimulate cytokine release and have adjuvant activity (Friedland et al., 1993; Carnelli Gebara et al., 2007). In addition, the abundant ER-located Hsp70 BiP homologue from plants has been shown to act as an adjuvant by activating dendritic cells and stimulating humoral immune responses in mice (McGowan, E. G., Gonzalez-Rabade, N., Nuttall, J., van Dolleweerd, C., Frigerio, L. and Ma, J. K-C., unpublished). Thirdly, there may be additional components in the plant extract that enhance uptake of the p24-Nef protein across the gut mucosal surface via M cells (Man et al., 2004).

Although transplastomic tobacco plants accumulate the p24Nef fusion protein to $\sim 40 \%$ of total soluble protein in leaves (Zhou et al., 2008), the removal of potentially toxic leaf components, such as polyphenols and alkaloids, was perceived to be necessary before oral administration. The LD50 values for oral administration of nicotine are reported to be $3.34,8.55$ and $65 \mathrm{mg} / \mathrm{kg}$ for the free base, the hemisulphate and the ditartrate, respectively (Registry of Toxic Effects of Chemical Substances 1985-1986). For a 20-g mouse, this equates to $0.07,0.17$ and $1.3 \mathrm{mg}$ (for the free base, the hemisulphate and the ditartrate). The measured amount of nicotine in the transplastomic tobacco leaves used in this study was $12.2 \mathrm{mmol} / \mathrm{g}$ fresh weight, which corresponds to $2 \mathrm{mg} / \mathrm{g}$ fresh weight or $1.7 \%$ dry weight. The partial purification procedure reduced this by $>95 \%$, so that the amount of nicotine administered per dose was $0.17 \mathrm{mg}$. This value is similar to the LD50 for nicotine hemisulphate, but no adverse effects on the mice were observed in any of the experiments. Unprocessed tobacco leaf homogenates have been administered orally to mice in most previous studies of oral vaccination with chloroplastexpressed antigens without any reports of toxic effects on the mice (Tregoning et al., 2005; Ruhlman et al., 2007; Arlen et al., 2008; Rosales-Mendoza et al., 2009; Davoodi-Semiromi et al., 2010). Guetard et al. (2008) have reported mice consuming $0.1 \mathrm{~g}$ per day of lyophilized tobacco leaves (corresponding to $1 \mathrm{~g}$ fresh weight) for at least 1 month without showing any evident health problems. This indicates that the nicotine in leaves and leaf extracts is not in a highly toxic form and is probably in a salt form with a much higher LD50. Most of these studies have used the tobacco cultivar Petite Havana, which contains about $1.7 \%$ nicotine on a dry weight basis, although Arlen et al. (2008) used the low-nicotine tobacco line LAMD 609, which contains only $0.06 \%$ nicotine (Aycock and Mulchi, 1998).

It has previously been suggested that about 100-fold more antigen would need to be administered orally to induce a protective immune response compared to the amount delivered by injection (Streatfield and Howard, 2003). However, only fivefold higher doses proved to be sufficient to generate an immune response when the plant-derived p24-Nef was used as an oral booster in the prime-boost strategy (Figures 3 and 4). Priming subcutaneously with p24 or Nef and boosting orally with p24-Nef was able to provoke a recall response, maintaining or increasing the antigen-specific $\lg G$ titres with each boost. Given the potent cross-clade humoral and T-cell immunity required for protection against HIV (Webster et al., 2005), plant-made HIV vaccines could find their niche as booster immunizations in prime-boost vaccine schedules. Oral administration is a very practical way to deliver vaccines, especially in developing countries, and does not require syringes, needles or trained personnel for administration. These features would favour the use of plant-derived oral vaccines for largescale immunization programs, particularly in developing countries with limited resources. Production of HIV antigens in plants should be a relatively inexpensive means of obtaining large quantities of protein required for widespread, multipledose vaccination in developing countries. Optimal doses of plant-derived antigens for stimulation of protective levels of antibody production lie in the range of $10-50 \mu \mathrm{g}$ for primary immunization and 50-150 $\mathrm{gg}$ for boosting regimes (Kong et al., 2001). With the transplastomic tobacco plants used in this study, grown under greenhouse conditions, $\sim 1 \mathrm{~g} \mathrm{p} 24$ and $\sim 6 \mathrm{~g}$ p24-Nef would be produced per plant (McCabe et al., 2008; Zhou et al., 2008). A hectare of transplastomic plants grown under similar conditions would be able to generate enough priming and boosting doses to immunize millions of people.

There are many options for processing plant tissues to allow for delivery of a well-characterized product. A purification strategy for chloroplast-derived p24 was shown to produce an antigen at $295 \%$ homogeneity (McCabe et al., 2008), suitable for subcutaneous administration. Enrichment techniques, such as acid precipitation and ion-exchange chromatography followed by freeze-drying, increased the concentration of chloroplastderived p24-Nef and removed $>95 \%$ of potentially toxic polyphenols and alkaloids, generating material suitable for oral administration. However, this processing of the leaf extracts removes one of the potential advantages of leaf material for oral delivery, that of bioencapsulation, which decreases the probability of degradation and dilution of the antigens within the digestive system. An alternative strategy avoiding processing leaf extracts to remove toxic components might include the production of transplastomic lines of palatable food materials, such as lettuce or tomato. Lettuce is probably the favoured crop for production of leaf-derived vaccine components (Ruhlman 
et al., 2007, 2010; Davoodi-Semiromi et al., 2010) using chloroplast transformation (Lilivelt et al., 2005; Kanamoto et al., 2006). The accumulation of foreign proteins up to $25 \%$ of total leaf protein has been obtained with lettuce (Ruhlman et al., 2010). Although p24-Nef accumulated at up to $40 \%$ of the total soluble protein of tomato leaves, lower amounts (up to $2.5 \%$ TSP) were observed in green tomato fruit (Zhou et al., 2008).

\section{Experimental procedures}

\section{Expression, extraction and purification of E. coli- derived p24 and Nef}

p24 with an N-terminal $\mathrm{His}_{10}$ tag was extracted and purified from a 2-L culture of E. coli BL21 (Studier and Moffatt, 1986) transformed with pET16bp24 (Zhou et al., 2008), incubated for $6 \mathrm{~h}$ at $37^{\circ} \mathrm{C}$ following induction with $1 \mathrm{~mm}$ IPTG. Inclusion bodies were solubilized in $8 \mathrm{~m}$ urea and His-tagged p24 purified on Ni-NTA agarose (Zhou et al., 2008). Urea was removed by two rounds of dialysis against $5 \mathrm{~L}$ of PBS. Lipopolysaccharide was removed by incubation for $1 \mathrm{~h}$ at room temperature with polymyxin $\mathrm{B}$ immobilized on $4 \%$ cross-linked agarose beads equilibrated with $0.2 \mathrm{M} \mathrm{NaH}_{2} \mathrm{PO}_{4} / 0.3 \mathrm{M}$ citrate buffer $\mathrm{pH}$ 7.0. The Limulus Amebocyte Lysate (LAL) QCL 1000 kit (Cambrex, Charles (ity, IA) was used to confirm the absence of endotoxins in the p24 preparation, following the manufacturer's instructions. Purified E. coli-derived Nef [EVA650, Strain III], produced by Prof. Volker Erfle (University of Munich, Germany) and Prof. Mauro Magnani (University of Urbino, Italy), was supplied by the National Institute for Biological Standards and Control (NIBSC, Potters Bar, Hertfordshire, UK).

\section{Purification of chloroplast-derived p24}

p24 was purified from 50- to 75-g batches of leaves of 12-week-old transplastomic tobacco (cultivar Maryland Mammoth) plants containing the pZF5 vector, by ammonium sulphate precipitation and cation-exchange chromatography on Mono S-Sepharose spin columns, as described by McCabe et al. (2008). The concentration of the purified preparation of chloroplast-derived p24 was determined from its absorbance at $280 \mathrm{~nm}$, using a value of 1.204 for a solution containing 1-mg p24/mL (Zhou et al., 2008).

\section{Partial purification of chloroplast-derived p24-Nef}

Chloroplast-derived p24-Nef fusion protein was extracted from $100 \mathrm{~g}$ of leaves of tobacco (N. tabacum L. cv. Petite Havana) containing the construct pZF7lox (Zhou et al., 2008) by homogenization in a Waring blender with $400 \mathrm{~mL}$ of extraction buffer [37.5 mm Tris- $\mathrm{HCl} \mathrm{pH}$ 7.5, $50 \mathrm{~mm} \mathrm{NaCl}, 15 \mathrm{~mm}$ EDTA, $75 \mathrm{~mm}$ trisodium citrate, $0.2 \%(\mathrm{w} / \mathrm{v})$ sodium thiosulphate, with $40-\mu \mathrm{g}$ $\mathrm{PMSF} / \mathrm{mL}$ ] (Chargelegue et al., 2005) supplemented with $20 \%$ $(\mathrm{W} / \mathrm{v})$ Dowex-1, a strong base anion-exchange resin that has been shown to bind phenols and other small molecules (Gray, 1978). The homogenate was centrifuged at $10000 \mathbf{g}$ for $30 \mathrm{~min}$ and the supernatant retained. The $\mathrm{pH}$ of the supernatant was shifted to $\mathrm{pH} 5.0$ with phosphoric acid, and precipitated proteins were removed by centrifugation at $13000 \mathbf{g}$ for $5 \mathrm{~min}$ at room temperature. The $\mathrm{pH}$ of the supernatant was adjusted to $\mathrm{pH} 7.0$ with $10 \mathrm{~m} \mathrm{NaOH}$ and aliquots loaded onto strong anion-exchange Vivapure Q spin columns (Sartorius Stedim, Epsom, Surrey, UK), retaining the flow-through. The partially purified material was dialysed against $10 \mathrm{~mm}$ $\left(\mathrm{NH}_{4}\right)_{2} \mathrm{CO}_{3}$ using SnakeSkin 3500 MWCO dialysis tubing (Pierce Biotechnology, Rockford, IL) at $4{ }^{\circ} \mathrm{C}$. The preparation was then frozen in liquid nitrogen and lyophilized in an Edwards EF4 Modulyo Freeze-drier with the chamber at $-60^{\circ} \mathrm{C}$.

The p24 content of the preparation was determined by p24specific ELISA, using mouse anti-p24 antiserum and horseradish peroxidase (HRP)-linked sheep anti-mouse IgG. Six serial twofold dilutions of the preparation were loaded in triplicate, together with E. coli p24 standards (AG6054; Aalto Bio Reagents, Rathfarnham Village, Dublin, Ireland). The protein content of plant extracts was determined using the bicinchoninic acid (BCA) Protein Assay kit (Pierce Biotechnology) with bovine serum albumen standards.

\section{Analysis of nicotine content}

The nicotine content of tobacco leaves and the p24-Nef preparation was determined by HPLC, following extraction into acidic methanol (Silva et al., 1998). Triplicate samples (10 mg) of freeze-dried leaves and the partially purified p24-Nef preparation were incubated with $1 \mathrm{~mL}$ of $40 \%$ methanol, $0.01 \% \mathrm{HCl}$ overnight at $20^{\circ} \mathrm{C}$ in the dark in an orbital shaker. The samples were centrifuged at $12000 \mathbf{g}$ for $10 \mathrm{~min}$, and the supernatant passed through a $0.2-\mathrm{mm}$ filter into an HPLC vial for analysis. Samples $(10 \mu \mathrm{L}$ ) were injected into the HPLC system (Accela; Thermo Fisher Scientific, Waltham, MA) fitted with a Luna C18 column $(100 \times 2 \mathrm{~mm}, 3 \mu \mathrm{m}$ particle size; Phenomenex, Torrance, CA), previously equilibrated with Buffer $A$ ( $2 \%$ orthophosphoric acid, adjusted to $\mathrm{pH} 7.40$ with triethylamine), and eluted at a flow rate of $250 \mu \mathrm{L} /$ min with a mixture of $80 \%$ (v/v) Buffer A and 20\% (v/v) Buffer B (100\% methanol). Nicotine was detected by its absorbance at $261 \mathrm{~nm}$ and eluted after 7-8 min. The amount of nicotine present was quantified by reference to standard amounts (39-2500 pmol) of nicotine (N3876; Sigma-Aldrich, Poole, Dorset, UK) analysed on the same column.

\section{SDS-PAGE and immunoblotting}

SDS-PAGE was performed according to Laemmli (1970) using Mini Protean electrophoresis equipment (Bio-Rad, Hercules, CA). Electrophoresis was carried out in $12 \%$ polyacrylamide gels, which were either stained with Coomassie brilliant blue or subjected to immunoblotting (Zhou et al., 2008). The membranes were incubated with either mouse monoclonal antibody to p24 (9044; Abcam, Cambridge, UK) or anti-Nef sera (NIBSC, Potters Bar, Hertfordshire, UK) diluted 1:1000, biotinylated sheep anti-mouse IgG (GE Healthcare, Little Chalfont, Buckinghamshire, UK) diluted $1: 1000$, streptavidin-biotinylated HRP complex (GE Healthcare) diluted 1:1000, and detected using a chemiluminescence reagent (PerkinElmer, Bar Hill, Cambridge, UK) and Kodak X-Omat autoradiography film (Sigma-Aldrich).

\section{Administration of plant-derived antigens to mice}

Female $\mathrm{C} 57 \mathrm{BL} / \mathrm{J}$ and $\mathrm{BALB} / \mathrm{C}$ mice were obtained from Harlan Laboratories (Bicester, Oxfordshire, UK) and kept in pathogenfree conditions at St. George's Hospital Medical School, London, according to Institutional and Home Office guidelines. Five-week-old C57BL/J mice were used for the experiment using only subcutaneous injection, whereas 8-week-old BALB/C mice were used for experiments involving oral administration by gavage. Mice were injected subcutaneously at the base of the tail with $100 \mu \mathrm{L}$ of a PBS solution containing the 
appropriate amount of purified antigen and $10 \mu \mathrm{g}$ of CTB (C9903; Sigma-Aldrich) as an adjuvant. For oral immunization, $50 \mu \mathrm{g}$ of the appropriate antigen (chloroplast-derived p24-Nef, E. coli-derived p24 or E. coli-derived Nef), together with $10-\mu \mathrm{g}$ CTB as adjuvant, were administered by gavage using roundedtip feeding needles. The immunization studies of plant-derived HIV antigens p24 and p24-Nef presented here were conducted in compliance with National and Institutional guidelines.

\section{Collection and processing of blood samples}

Mice were tail-bled at different times throughout the immunological analysis. Blood samples were incubated at $37^{\circ} \mathrm{C}$ for $1 \mathrm{~h}$ to allow for clotting. Samples were then incubated at $4{ }^{\circ} \mathrm{C}$ overnight and centrifuged at $23000 \mathrm{~g}$ at $4{ }^{\circ} \mathrm{C}$. The supernatant was recovered and stored at $-20^{\circ} \mathrm{C}$. For culling, mice were anaesthetized by placing them in a chamber containing isoflurane (Merial Animal Health, Harlow, Essex, UK), $\mathrm{O}_{2}$ and $\mathrm{N}_{2} \mathrm{O}$. They were culled by cardiac puncture (keeping the blood for further processing and analysis) and subjected to neck and spinal chord dislocation.

\section{Collection and processing of faecal and vaginal samples}

Five fresh faecal pellets were collected from each individual mouse 1 or 2 days before culling, and suspended in 4- $\mu$ L PBS with protease inhibitor cocktail (Roche, Burgess Hill, UK) per mg of faecal pellet. The sample was incubated on ice for $1 \mathrm{~h}$, centrifuged twice at $27000 \mathrm{~g}$ for $7 \mathrm{~min}$ and the supernatant stored at $-80^{\circ} \mathrm{C}$ before analysis. Vaginal washes were obtained from individual anaesthetized mice by washing the vagina three times with $30-\mu \mathrm{L}$ volumes of PBS with protease inhibitor cocktail (Roche). The samples were incubated on ice for $30 \mathrm{~min}$, centrifuged at $30000 \mathrm{~g}$ for $10 \mathrm{~min}$ and the supernatant stored at $-80^{\circ} \mathrm{C}$ before analysis. Faecal and vaginal samples were analysed for p24- and Nef-specific IgA by ELISA, using biotinconjugated goat anti-mouse IgA (product 1040-08; SouthernBiotech, Birmingham, AL) and streptavidin-horse radish peroxidase (product DY998; R\&D Systems, Minneapolis, MN).

\section{ELISA of murine serum samples}

Serum responses in mice were measured by antigen-specific ELISA, as described by Obregon et al. (2006). Wells were coated with chloroplast-derived p24, E. coli-derived p24 or E. coliderived Nef, and incubated in duplicate with twofold serial dilutions of the serum samples. Bound p24- and Nef-specific antibodies were detected with the following alkaline-phosphataseconjugated antibodies: for whole IgG responses, sheep antimouse g-lgG (AP272; The Binding Site, Birmingham, UK); for IgG1 responses, rabbit anti-mouse a-lgG1 (AP273; The Binding Site); for IgG2a responses, rabbit anti-mouse a-lgG2a (MP003; The Binding Site). Results from the immunoassays were expressed as endpoint titres, defined as the reciprocal of the highest analyte dilution that gave a reading above the cut-off (Frey et al., 1998). The cut-off values were considered to be those of the background (pre-immunization sera) or negative control group.

\section{Acknowledgements}

We thank Daniel Karcher (MPI-MPP, Golm), Miranda Poage (NUIM, Ireland), Elena Stylianou (St. George's, London), Jesus Agustin Badillo-Corona, Juliette Jouhet, Ellie Mott, Sue Aspinall and Jack Westwood (Plant Sciences, Cambridge) for their help and guidance. We thank the Programme EVA Centre for AIDS Reagents, NIBSC, UK, supported by the EC FP6/7 Europrise Network of Excellence, for Nef and anti-Nef antibodies. The work described in this paper work was supported by the European Commission (grant number LSHB-CT-2003-503565) as part of the Pharma-Planta project. NG-R was supported by scholarships from CONACyT Mexico, the Gates Cambridge Trust, the Cambridge Overseas Trust and the Pharma-Planta Consortium.

\section{References}

Arlen, P.A., Singleton, M., Adamovicz, J.J., Ding, Y., Davoodi-Semiromi, A. and Daniell, H. (2008) Effective plague vaccination via oral delivery of plant cells expressing F1-V antigens in chloroplasts. Infect. Immun. 76, 36403650 .

Asakura, Y., Hinkula, J., Leandersson, A., Fukushima, J., Okuda, K. and Wahren, B. (1997) Induction of HIV-1 specific mucosal immune responses by DNA vaccination. Scand. J. Immunol. 46, 326-330.

Aycock, M.K. and Mulchi, C.L. (1998) Registration of LAMD 609 tobacco germplasm. Crop Sci. 38, 904.

Bock, R. and Warzecha, H. (2010) Solar-powered factories for new vaccines and antibiotics. Trends Biotechnol. 28, 246-252.

Carnelli Gebara, V.C.B., Risoléo, L., Lopes, A.P.Y., Ferreira, V.R.F., Quintillo, W., Lépine, F., Silva, W.D. and Raw, I. (2007) Adjuvant and immunogenic activities of the $73 \mathrm{kda} \mathrm{N}$-terminal a-domain of BrkA autotransporter and Cpn60/60 kDa chaperonin of Bordetella pertussis. Vaccine, 25, 621-629.

Chargelegue, D., Drake, P.M.W., Obregon, P., Prada, A., Fairweather, N. and Ma, J.K.C. (2005) Highly immunogenic and protective recombinant vaccine candidate expressed in transgenic plants. Infect. Immun. 73, 5915-5922.

Crandall, K.A. (2001) Human immunodeficiency viruses (HIV). In: Encyclopedia of Life Sciences (Harper, D., ed.), pp. 1-7. London: Nature Publishing Group.

Daniell, H., Singh, N.D., Mason, H. and Streatfield, S.J. (2009) Plant-made vaccine antigens and biopharmaceuticals. Trends Plant Sci. 14, 669-679.

Davoodi-Semiromi, A., Schreiber, M., Nalapalli, S., Verma, D., Singh, N.D., Banks, R.K., Chakrabarti, D. and Daniell, H. (2010) Chloroplast-derived vaccine antigens confer dual immunity against cholera and malaria by oral or injectable delivery. Plant Biotechnol. J. 8, 223-242.

Djordjevic, M.V. and Doran, K.A. (2009) Nicotine content and delivery across tobacco products. In: Nicotine Psychopharmacology. Handbook of Experimental Pharmacology, Vol. 192 (Henningfield, J.E., London, E.D. and Pogun, S., eds), pp. 61-82. Berlin: Springer.

Ellis, R.J. (1990) Molecular chaperones: the plant connection. Science, 250, 954-959.

Essex, M. (1999) Human immunodeficiency viruses in the developing world. Adv. Virus Res. 53, 71-88.

Frey, A., Canzio, J.D. and Zurakowski, D. (1998) A statistically defined endpoint titre determination method for immunoassays. J. Immunol. Methods, 221, 35-41.

Friedland, J.S., Shattock, R., Remick, D.G. and Griffin, G.E. (1993) Mycobacterial $65-k D$ heat shock protein induces release of proinflammatory cytokines from human monocytic ells. Clin. Exp. Immunol. 91, 58-62.

Gallo, R.C. (2006) A reflection on HIV/AIDS research after 25 years. Retrovirology, 3, 1-7

Geyer, M. and Peterlin, B.M. (2001) Domain assembly, surface accessibility and sequence conservation in full length HIV-1 Nef. FEBS Lett. 496, 91-95.

Girard, M.P., Osmanov, S.K. and Kieny, M.P. (2006) A review of vaccine research and development: the human immunodeficiency virus (HIV). Vaccine, 24, 4062-4081.

Gray, J.C. (1978) Absorption of polyphenols by polyvinylpyrrolidone and polystyrene resins. Phytochemistry, 17, 495-497.

Guetard, D., Greco, R., Gonzalez, M.C., Celli, S., Kostrzak, A., LangladeDemoyen, P., Sala, F., Wain-Hobson, S. and Sala, M. (2008) 
Immunogenicity and tolerance following HIV-1/HBV plant-based oral vaccine administration. Vaccine, 26, 4477-4485.

Haglund, K., Leiner, I., Kerksiek, K., Buonocore, L., Pamer, E. and Rose, J.K. (2002) Robust recall and long-term memory T-cell responses induced by prime-boost regimens with heterologous live viral vectors expressing Human immunodeficiency virus type $1 \mathrm{Gag}$ and Env proteins. J. Virol. 76, 7506-7517.

Hanke, T. and McMichael, A.J. (2000) Design and construction of an experimental HIV-1 vaccine for a year-2000 clinical trial in Kenya. Nat. Med. 6, 951-955.

Hausdorf, G., Gewiess, A., Wray, V. and Porstmann, T. (1994) A recombinant human immunodeficiency virus type-1 capsid protein (rp24): its expression, purification and physico-chemical characterization. J. Virol. Methods, 50, $1-9$.

Hel, Z., Johnson, J.M., Tryniszewska, E., Tsai, W., Harrod, R., Fullen, J., Tartaglia, J. and Franchini, G. (2002a) A novel chimeric Rev, Tat, and Nef (Retanef) antigen as a component of an SIV/HIV vaccine. Vaccine, 20, 3171-3186.

Hel, Z., Nacsa, J., Tryniszewska, E., Tsai, W.P., Parks, R.W., Montefiori, D.C., Felber, B.K., Tartaglia, J., Pavlakis, G.N. and Franchini, G. (2002b) Containment of simian immunodeficiency virus infection in vaccinated macaques: correlation with the magnitude of virus-specific pre- and post challenge CD4+ and CD8+ T cell responses. J. Immunol. 169, 47784787 .

Hemmingsen, S.M., Woolford, C., van der Vies, S., Tilly, K., Dennis, D.T., Georgopoulos, C.P., Hendrix, R.W. and Ellis, R.J. (1988) Homologous plant and bacterial proteins chaperone oligomeric protein assembly. Nature, 333, 330-334.

Holmgren, J., Lycke, N. and Czerkinsky, C. (1992) Cholera toxin and cholera B subunits as oral-mucosal adjuvant and antigen vector systems. Vaccine, 11, 1179-1184.

Iroegbu, J., Birk, M., Lazdina, U., Sonnerborg, A. and Sallberg, M. (2000) Variability and immunogenicity of human immunodeficiency virus type 1 p24 gene quasispecies. Clin. Diagn. Lab. Immunol. 7, 377-383.

Iwarson, S., Tabor, E., Thomas, H.C., Snoy, P. and Gerety, R.J. (1985) Protection against hepatitis $B$ virus infection by immunization with hepatitis b core antigen. Gastroenterology, 88, 763-767.

Johnston, M. and Fauci, A.S. (2007) An HIV vaccine: evolving concepts. New Engl. J. Med. 356, 2073-2081.

Kanamoto, H., Yamashita, A., Asao, H., Okumura, S., Takase, H., Hattori, M., Yokota, A. and Tomizawa, K. (2006) Efficient and stable transformation of Lactuca sativa L. CV. Cisco (lettuce) plastids. Transgenic Res. 15, 205-217

Kohleisen, B., Gaedigk-Nitschko, K., Ohlmann, M., Gotz, E., Ostolaza, H., Goni, F.M. and Erfle, V. (1996) Heparin-binding capacity of the HIV-1 Nefprotein allows one-step purification and biochemical characterization. J. Virol. Methods, 60, 89-101.

Kong, Q., Richter, L., Yang, Y.F., Arntzen, C.J., Mason, H.S. and Thanavala, Y. (2001) Oral immunization with hepatitis B surface antigen expressed in transgenic plants. Proc. Natl Acad. Sci. USA, 98, 11539-11544.

Laemmli, U.K. (1970) Cleavage of structural proteins during the assembly of the head of the bacteriophage T4. Nature, 227, 680-685.

Lilivelt, C.L.C., McCabe, M.S., Newell, C.A., de Snoo, C.B., van Dun, K.M.P., Birch-Machin, I., Gray, J.C., Mills, K.H.G. and Nugent, J.M. (2005) Stable plastid transformation in lettuce (Lactuca sativa L.). Plant Mol. Biol. 58, 763-774.

Man, A.L., Prieto-Garcia, M.A. and Nicoletti, C. (2004) Improving M cell mediated transport across mucosal barriers: do certain bacteria hold the keys? Immunology, 113, 15-22.

Marczinovits, I., Boros, I., El Jarrah, F., Fust, G. and Molnar, J. (1993) Expression in Escherichia coli and in vitro processing of HIV-1 p24 fusion protein. J. Biotechnol. 31, 225-232.

Marshall, J.S., DeRocher, A.E., Keegstra, K. and Vierling, E. (1990) Identification of heat shock protein hsp70 homologues in chloroplasts. Proc. Natl Acad. Sci. USA, 87, 374-378.

Marusic, C., Nutall, J., Buriani, G., Lico, C., Lombardi, R., Baschieri, S., Benevuto, E. and Frigerio, L. (2007) Expression, intracellular targeting and purification of HIV Nef variants in tobacco cells. BMC Biotechnol. 7, 1-12.
McCabe, M.S., Klaas, M., Gonzalez-Rabade, N., Poage, M., Badillo-Corona, J.A., Zhou, F., Karcher, D., Bock, R., Gray, J.C. and Dix, P.J. (2008) Plastid transformation of high-biomass tobacco variety Maryland Mammoth for production of human immunodeficiency virus type 1 (HIV-1) p24 antigen. Plant Biotechnol. J. 6, 914-929.

McMichael, A.J. and Hanke, T. (2003) HIV vaccines 1983-2003. Nat. Med. 9, 874-880.

Meyers, A., Chakauya, E., Shephard, E., Tanzer, F.L., Maclean, J., Lynch, A., Williamson, A.-L. and Rybicki, E.P. (2008) Expression of HIV-1 antigens in plants as potential subunit vaccines. BMC Biotechnol. 8, 1-15.

Mills, H.R. and Jones, I.M. (1990) Expression and purification of p24, the core protein of HIV, using a baculovirus-insect cell expression system. AIDS, 4, 1125-1131.

Murray, K., Bruce, S.A., Wingfield, P., van Eerd, P., de Reus, A. and Schellekens, H. (1987) Protective immunization against hepatitis B with an internal antigen of the virus. J. Med. Virol. 23, 101-107

Novitsky, V., Rybak, N., McLane, M.F., Gilbert, P., Chigwedere, P., Klein, I., Gaolekwe, S., Chang, S.Y., Peter, T., Thior, I., Ndung'u, T., Vannberg, F., Foley, B.T., Marlink, R., Lee, T.H. and Essex, M. (2001) Identification of human immunodeficiency virus type 1 subtype C Gag-, Tat-, Rev-, and Nefspecific elispot-based cytotoxic T-lymphocyte responses for AIDS vaccine design. J. Virol. 75, 9210-9228.

Obregon, P., Chargelegue, D., Drake, P.M., Prada, A., Nuttall, J., Frigerio, L. and Ma, J.K.C. (2006) HIV-1 p24-immunoglobulin fusion molecule: a new strategy for plant-based protein production. Plant Biotechnol. J. 4, 195-207.

Oey, M., Lohse, M., Kreikemeyer, B. and Bock, R. (2009) Exhaustion of the chloroplast protein synthesis capacity by massive expression of a highly stable protein antibiotic. Plant J. 57, 436-445.

Pal, R., Wang, S., Kalyanaraman, V.S., Nair, B.C., Whitney, S., Keen, T., Hocker, L., Hudacik, L., Rose, N., Cristillo, A., Mboudjeka, I., Shen, S., Wu-Chou, T., Montefiori, D., Mascola, J., Lu, S. and Markham, P. (2005) Polyvalent DNA prime and envelope protein boost HIV-1 vaccine elicits humoral and cellular responses and controls plasma viremia in rhesus macaques following rectal challenge with an R5 SHIV isolate. J. Med. Primatol. 34, 226-236.

Rosales-Mendoza, S., Alpuche-Solis, A.G., Soria-Guerra, R.E., Moreno-Fierros, L., Martinez-Gonzalez, L., Herrera-Diaz, A. and Korban, S.S. (2009) Expression of an Escherichia coli antigenic fusion protein comprising the heat labile toxin B subunit and the heat stable toxin, and its assembly as a functional oligomer in transplastomic tobacco plants. Plant J. 57, 45-54.

Ruhlman, T., Ahangari, R., Devine, A., Samsam, M. and Daniell, H. (2007) Expression of cholera toxin B-proinsulin fusion protein in lettuce and tobacco chloroplasts - oral administration protects against development of insulinitis in non-obese diabetic mice. Plant Biotechnol. J. 5, 495-510.

Ruhlman, T., Verma, D., Samson, N. and Daniell, H. (2010) The role of heterologous chloroplast sequence elements in transgene integration and expression. Plant Physiol. 152, 2088-2104.

Russell, S.M. and Liew, F.Y. (1980) Cell cooperation in antibody responses to influenza virus. Priming of helper T cells by internal components of virion. Eur. J. Immunol. 10, 791-796.

Silva, G.L., Lee, I.-S. and Kinghorn, A.D. (1998) Special problems with the extraction of plants. In: Natural Products Isolation. Methods in Biotechnology Vol. 4 (Cannell, R.J.P., ed.), pp. 343-363. New Jersey: Humana Press.

Spira, S., Waingerb, M.A., Loemba, H., Turner, D. and Brenner, B.G. (2003) Impact of clade diversity on HIV-1 virulence, antiretroviral drug sensitivity and drug resistance. J. Antimicrob. Chemother. 51, 229-240.

Streatfield, S.J. and Howard, J.A. (2003) Plant-based vaccines. Int. J. Parasitol. 33, 479-493.

Studier, F.W. and Moffatt, B. (1986) Use of bacteriophage T7 RNA polymerase to direct selective high-level expression of cloned genes. J. Mol. Biol. 189, 113-130.

Suzue, K. and Young, R.A. (1996) Adjuvant-free hsp70 fusion protein system elicits humoral and cellular immune responses to HIV-1 p24. J. Immunol. 156, 873-879.

Takeda, A., Igarashi, H., Nakamura, H., Kano, M., lida, A., Hirata, T., Hasegawa, M., Nagai, Y. and Matano, T. (2003) Protective efficacy of an AIDS vaccine, a single DNA priming followed by a single booster with a 
recombinant replication-defective Sendai virus vector, in a macaque AIDS model. J. Virol. 77, 9710-9715.

Tregoning, J.S., Clare, S., Bowe, F., Edwards, L., Fairweather, N., Qazi, O., Nixon, P.J., Maliga, P., Dougan, G. and Hussell, T. (2005) Protection against tetanus toxin using a plant-based vaccine. Eur. J. Immunol. 35, 1320-1326.

Walmsley, A.M. and Arntzen, C.J. (2003) Plant cell factories and mucosal vaccines. Curr. Opin. Biotechnol. 14, 145-150.

Wang, Y., Kelly, C.G., Singh, M., McGowan, E.G., Carrara, A.-S., Bergmeier, L.A. and Lehner, T. (2002) Stimulation of Th1-polarizing cytokines, CC-chemokines, maturation of dendritic cells, and adjuvant function by the peptide binding fragment of heat shock protein 70. J. Immunol. 169, 2422-2429.

Weber, J., Cheingsong-Popov, R., Callow, D., Adams, S., Patou, G., Hodgkin, K., Martin, S., Gotch, F. and Kingsman, A. (1995) Immunogenicity of the yeast recombinant $\mathrm{p} 17 / \mathrm{p} 24$ : Ty virus-like particles (p24-VLP) in healthy volunteers. Vaccine, 13, 831-834.
Webster, D.E., Thomas, M.C., Pickering, R., Whyte, A., Dry, I.B., Gorry, P.R. and Wesselingh, S.L. (2005) Is there a role for plant-made vaccines in the prevention of HIV/AIDS? Immunol. Cell Biol. 83, 239-247.

WHO (2009) World Health Organization statistics. http://www.who.int/gho/ en/. last accessed: 16 March 2011.

Zhang, G., Leung, C., Murdin, L., Rovinski, B. and White, K.A. (2000) In planta expression of HIV-1 p24 protein using an RNA plant virus-based vector. Mol. Biotechnol. 14, 99-107.

Zhang, G.G., Rodrigues, L., Rovinski, B. and White, K.A. (2002) Production of HIV-1 p24 protein in transgenic tobacco plants. Mol. Biotechnol. 20, 131136.

Zhou, F., Badillo-Corona, J.A., Karcher, D., Gonzalez-Rabade, N., Piepenburg, K., Borchers, A.M.I., Maloney, A.P., Kavanagh, T.A., Gray, J.C. and Bock, R. (2008) High-level expression of human immunodeficiency virus antigens from the tobacco and tomato plastid genomes. Plant Biotechnol. J. 6, 897913. 